\title{
DLCO: adjust for lung volume, standardised reporting and interpretation
}

\author{
To the Editor:
}

The American Thoracic Society (ATS) and European Respiratory Society (ERS) should be congratulated on updating standards for diffusing capacity of the lung for carbon monoxide (DLCO) [1]. I agree that "Besides varying with age, sex, height and possible ethnicity, DLCO also changes with Hb, lung volume, $\mathrm{COHb}, \mathrm{PIO}_{2} \ldots$, exercise and body position." and that "adjustments for these factors be made in the predicted rather than the measured DLCO". Reporting transfer coefficient of the lung for carbon monoxide (KCO) rather than DLCO/alveolar volume $(V \mathrm{~A})$ will help get away from the mistaken notion that $D \mathrm{LCO} / V_{\mathrm{A}}$ "corrects" DLCO for lung volume [2]. While the new standards describe how to adjust predicted DLCO for haemoglobin $(\mathrm{Hb}), \mathrm{COHb}$ and inspired oxygen tension $\left(\mathrm{PIO}_{2}\right)$, it does not discuss how to adjust predicted DLCO and KCO for lung volume.

The following equations [3] were included in the 2005 ATS/ERS DLCO standards [4], and describe how to adjust DLCO and KCO for lung volume. They were developed studying normal subjects with experimental reductions in inspired volume $\left(V_{\mathrm{I}}\right.$; and thus $\left.V_{\mathrm{A}}\right)$ and fit the model that DLCO and KCO change in a manner expected from having DLCO reduced proportionate to the surface area for gas exchange with the capillary blood component unchanged. Mathematically, they result in DLCO \% predicted for lung volume equaling $\mathrm{KCO} \%$ predicted for lung volume when using the equation $\mathrm{KCO}$ (predicted)=DLCO(predicted)/ $\mathrm{VA}$ (predicted).

$D \mathrm{LCO}[$ predicted for lung volume $]=D \mathrm{LCO}[$ predicted $] \times(0.58+0.42 \times(V \mathrm{Am} / V \mathrm{Ap}))$

$K \mathrm{CO}[$ predicted for lung volume $]=K \mathrm{CO}[$ predicted $] \times\left(0.42+0.58 /\left(V_{\mathrm{Am}} / V_{\mathrm{Ap}}\right)\right)$

with $V A m / V A p=$ measured $V A /$ predicted $V A$.

For example, at VA $50 \%$ of predicted, the DLCO predicted for lung volume is $80 \%$ and KCO is $160 \%$ of that for VA $100 \%$ of predicted.

The standards require reporting DLCO and KCO (adjusted, predicted) with specification of the adjustments. Additional reporting requirements should include DLCO (\% of adjusted predicted) and VA (\% predicted).

Neither the 2005 nor the current standards address how to report DLCO and KCO adjusted for lung volume, or how to interpret DLCO.

In addition to knowing \% predicted DLCO and KCO adjusted for all factors except lung volume, it is also very helpful to know \% predicted DLCO and KCO when also adjusted for lung volume [2]. Just as adjusting predicted DLCO and KCO for haemoglobin in an anaemic patient yields a better indication of the lung's ability of gas exchange, adjusting DLCO and KCO for lung volume in a patient with low lung volume yields a better indication of the lung's ability of gas exchange.

A shorter nomenclature is needed for DLCO and KCO \% predicted also adjusted for lung volume.

I propose DACO and KACO to refer to DLCO and KCO predicted values that have been adjusted for lung volume (the "A" refers to adjusted for lung volume.)

Reporting requirements should include DACO (adjusted, predicted), KACO (adjusted, predicted), as well as DACO (\% of adjusted predicted) and KACO (\% of adjusted predicted).

@ERSpublications

DLCO reports and interpretation should be standardised and include adjusting predicted DLCO and KCO for lung volume http://ow.ly/ywTA30cOh44

Cite this article as: Johnson DC. DLCO: adjust for lung volume, standardised reporting and interpretation. Eur Respir J 2017; 50: 1700940 [https://doi.org/10.1183/13993003.00940-2017]. 
The new standards recommend development of a standardised common report form. I propose the following, one when $\mathrm{Hb}$ is not measured (box 1) and a second when $\mathrm{Hb}$ is measured (box 2), with both including $\%$ of FVC for VI if spirometry was done the same day

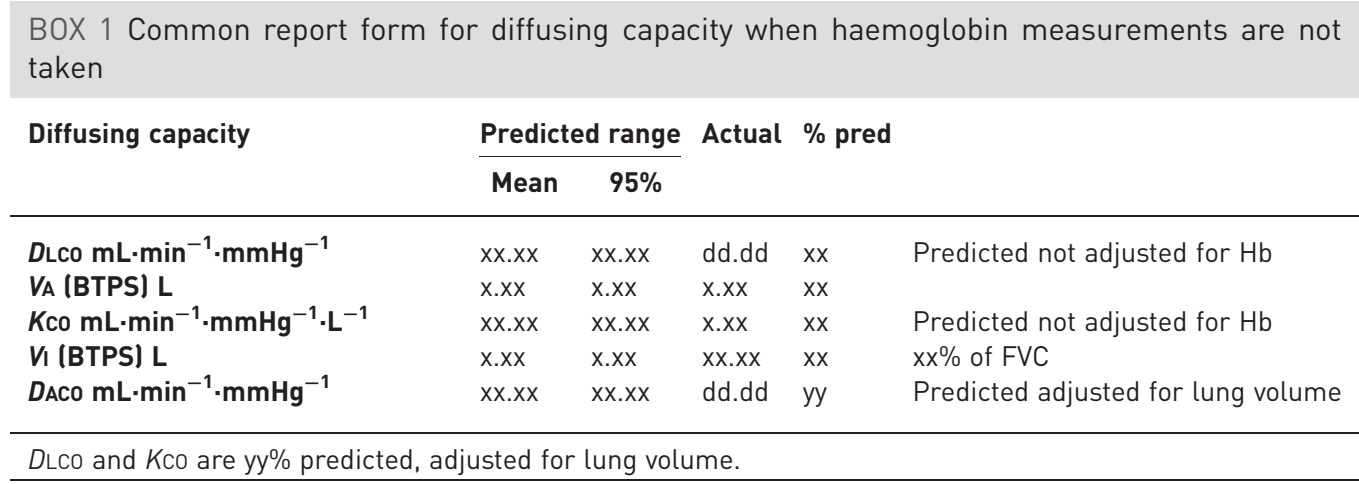

\begin{tabular}{|c|c|c|c|c|c|}
\hline \multirow[t]{2}{*}{ Diffusing capacity } & \multicolumn{2}{|c|}{ Predicted range } & \multirow[t]{2}{*}{ Actual } & \multirow[t]{2}{*}{$\%$ pred } & \multirow[t]{2}{*}{ Hb xx.x from D-MON-YYYY } \\
\hline & Mean & $95 \%$ & & & \\
\hline \multirow{6}{*}{$\begin{array}{l}\text { DLCO } \mathrm{mL} \cdot \mathrm{min}^{-1} \cdot \mathrm{mmHg}^{-1} \\
\text { DLCO } \mathrm{mL} \cdot \mathrm{min}^{-1} \cdot \mathrm{mmHg}^{-1} \\
\text { VA (BTPS) L } \\
\text { Kco } \mathrm{mL} \cdot \mathrm{min}^{-1} \cdot \mathrm{mmHg}^{-1} \cdot \mathrm{L}^{-1} \\
\text { VI (BTPS) L } \\
\text { DACO } \mathrm{mL} \cdot \mathrm{min}^{-1} \cdot \mathrm{mmHg}^{-1}\end{array}$} & $x X . X X$ & $x x . x x$ & \multirow{2}{*}{$\begin{array}{l}\text { dd.dd } \\
\text { dd.dd }\end{array}$} & $x x$ & \multirow{2}{*}{$\begin{array}{l}\text { Predicted not adjusted for } \mathrm{Hb} \\
\text { Predicted adjusted for } \mathrm{Hb}\end{array}$} \\
\hline & $x x . x x$ & $x x . x x$ & & $x x$ & \\
\hline & $x . x x$ & $x . x x$ & $x . x x$ & $x x$ & \multirow{4}{*}{$\begin{array}{l}\text { Predicted adjusted for } \mathrm{Hb} \\
\mathrm{x} \% \text { of } \mathrm{FVC} \\
\text { Predicted adjusted for lung volume and } \\
\mathrm{Hb}\end{array}$} \\
\hline & $x x \cdot x x$ & $x x \cdot x x$ & $x . x x$ & $x x$ & \\
\hline & $x . x x$ & $x . x x$ & $x . x x$ & $x x$ & \\
\hline & $x x . x x$ & $x x . x x$ & dd.dd & yy & \\
\hline
\end{tabular}

$D \mathrm{LCO}$ and $\mathrm{KCO}$ are $\mathrm{yy} \%$ predicted, adjusted for lung volume and $\mathrm{Hb}$.

For both reports, if DLCO and KCO predicted were also adjusted for COHb and/or PIO2, then a line saying "Predicted DLCO and KCO also adjusted for ..." should appear at the end, which includes the data used to make the adjustment, such as "COHb of $2.6 \%$ and altitude of $2000 \mathrm{~m}$." The $95 \%$ values are the lower limit of normal (LLN), with $D$ ACO $[L L N]=D A C O[$ adjusted,predicted] $\times D$ LCO $[\mathrm{LLN}] /$ DLCO[predicted].

There is not a clear consensus on interpretation of DLCO. I recommend the following algorithm to interpret DLCO, with DLCO \% predicted, adjusted and LLN the lower limit of normal (box 3).

\begin{tabular}{|c|c|}
\hline$D \mathrm{LCO} \geqslant 80 \%$ and $\geqslant$ LLN & $D \mathrm{Lco}$ is normal \\
\hline DLCO $<80 \%$ but $\geqslant$ LLN & D Lco is near lower limit of normal \\
\hline$D$ LCO $\geqslant 60 \%,<80 \%$, and $<$ LLN & DLco is mildly reduced \\
\hline$D$ LCO $\geqslant 40 \%,<60 \%$, and $<$ LLN & DLco is moderately reduced \\
\hline$D$ LCO $<40 \%$ & DLCo is severely reduced \\
\hline
\end{tabular}

If DLCO is not normal, and DLCO adjusted for lung volume (DACO) is above the LLN as \% predicted, then add phrase "due to low lung volume".

If DLCO is not normal, and DLCO adjusted for lung volume is below the LLN as \% predicted but more than $10 \%$ predicted greater than DLCO, then add phrase "in part due to low lung volume".

As a co-author of the 2005 ERS/ATS DLCO standards, I believe including adjustments of DLCO for lung volume and standardised reports and interpretation would improve the clinical value of DLCO. 
Douglas C. Johnson

Baystate Medical Center, Springfield, MA, USA.

Correspondence: Douglas C. Johnson, Baystate Medical Center, 759 Chestnut Street, Springfield, MA 01199-0001, USA. E-mail: dougjohnsonmd@gmail.com

Received: May 082017 | Accepted after revision: May 312017

Conflict of interest: None declared.

\section{References}

1 Graham BL, Brusasco V, Burgos F, et al. 2017 ERS/ATS Standards for single-breath carbon monoxide uptake in the lung. Eur Respir J 2017; 49: 1600016.

2 Hughes M, Pride N. Examination of the carbon monoxide diffusing capacity (DLCO) in relation to its KCO and VA components. Am J Respir Crit Care Med 2012; 186: 132-139.

3 Johnson DC. Importance of adjusting carbon monoxide diffusing capacity (DLCO) and carbon monoxide transfer coefficient (KCO) for alveolar volume. Respir Med 2000; 94: 28-37.

4 MacIntyre N, Crapo R, Viegi G, et al. Standardisation of the single-breath determination of carbon monoxide uptake in the lung. Eur Respir J 2005; 26: 720-735.

Copyright @ERS 2017

From the authors:

D.C. Johnson proposed that an adjustment of the predicted value for the diffusing capacity of the lung for carbon monoxide (DLCO) based on the measured and predicted lung volume be included in the report of DLCO test results. An interpretation algorithm is also proposed.

The rationale is based on the observation that a decreased inspired volume in normal subjects reduces DLCO and that this reduction can be predicted using a linear function of the measured alveolar lung volume $(V \mathrm{~A})$ divided by the predicted $V \mathrm{~A}$. While this formula may be applicable for normal, healthy lungs and may potentially adjust for effects of reductions in $V$ A due to weakness, chest wall deformities or reduced effort, it is unlikely to be applicable in patients with reduced $V$ A due to pathological processes that also impact the distribution of ventilation, the distribution of perfusion and the development of heterogeneous parenchymal changes in the lung. As Hughes and Pride [1] noted, "any 'correction' of the DLCO for volume must take into account the reason for the volume deficit." Volume adjustment equations for DLCO developed from submaximal inhalation manoeuvres in normal subjects do not consider other mechanisms for a reduced $V A$.

The 2017 European Respiratory Society (ERS)/American Thoracic Society (ATS) standards for single-breath carbon monoxide uptake in the lung [2] describe technical standards for the measurement of DLCO. The interpretation of DLCO was not included in the mandate of the ERS/ATS task force in the development of these standards. Nevertheless, the reporting of the results must provide all of the necessary information for their interpretation.

The standards address the need for the subject to achieve maximal inhalation of test gas. A failure to reach full inflation to total lung capacity is a reason to repeat the manoeuvre rather than applying a volume correction to the predicted DLCO. Reporting the VA and its z-score together with the DLCO allows the reviewer to interpret the DLCO in the context of whether the VA is reduced, normal or increased. It continues to be the opinion of the ERS/ATS DLCO task force that this information is sufficient for the interpretation of DLCO.

Brian L. Graham ${ }^{1}$, Vito Brusasco ${ }^{2}$, Felip Burgos ${ }^{3}$, Brendan G. Cooper ${ }^{4}$, Robert Jensen ${ }^{5}$, Adrian Kendrick ${ }^{6}$, Neil R. MacIntyre ${ }^{7}$, Bruce R. Thompson ${ }^{8}$ and Jack Wanger?

@ERSpublications

A correction of the predicted value for DLCo based on the measured lung volume is not recommended http://ow.ly/KFn730cPJ9n

Cite this article as: Graham BL, Brusasco V, Burgos F, et al. DLCO: adjust for lung volume, standardised reporting and interpretation. Eur Respir J 2017; 50: 1701144 [https://doi.org/10.1183/13993003.011442017]. 
${ }^{1}$ Division of Respirology, Critical Care and Sleep Medicine, University of Saskatchewan, Saskatoon, SK, Canada. ${ }^{2}$ Dept of Internal Medicine, University of Genoa, Genoa, Italy. ${ }^{3}$ Respiratory Diagnostic Center, Hospital Clínic, Institut d'Investigacions Biomèdiques August Pi i Sunyer (IDIBAPS), University of Barcelona, Barcelona, Spain. ${ }^{4}$ Lung Function and Sleep, Queen Elizabeth Hospital, University of Birmingham, Birmingham, UK. ${ }^{5}$ Pulmonary Division, University of Utah, Salt Lake City, UT, USA. ${ }^{6}$ Dept of Respiratory Medicine, Bristol Royal Infirmary, Bristol, UK. ${ }^{7}$ Pulmonary, Allergy and Critical Care Medicine, Duke University Medical Center, Durham, NC, USA. ${ }^{8}$ Allergy, Immunology and Respiratory Medicine, The Alfred Hospital and Monash University, Melbourne, Australia. ${ }^{9}$ Consultant, Rochester, MN, USA.

Correspondence: Brian L. Graham, University of Saskatchewan, Respirology, Critical Care and Sleep Medicine, 5th Floor, Ellis Hall, Saskatoon, Saskatchewan S7N 0W8, Canada. E-mail: brian.graham@usask.ca

Received: June 122017 | Accepted after revision: June 132017

Conflict of interest: Disclosures can be found alongside this article at erj.ersjournals.com

\section{References}

1 Hughes M, Pride N. Examination of the carbon monoxide diffusing capacity ( $D$ LCO) in relation to its KCO and VA components. Am J Respir Crit Care Med 2012; 186: 132-139.

2 Graham BL, Brusasco V, Burgos F, et al. 2017 ERS/ATS standards for single-breath carbon monoxide uptake in the lung. Eur Respir J 2017; 49: 1600016. 